\title{
Perceived social support and depressive symptoms in Chinese patients with ovarian cancer and the mediating role of resilience
}

\section{Xiaoyan Pang}

The First Affiliated Hospital of China Medical University

Haiyan Dong

The First Affiliated Hospital of China Medical University

\section{Lei Deng}

The First Affiliated Hospital of China Medical University

\section{Yi Zhang ( $\nabla$ syzi@163.com )}

First Affiliated Hospital of China Medical University https://orcid.org/0000-0003-1150-6042

\section{Research article}

Keywords: ovarian cancer, depression, resilience, perceived social support

Posted Date: February 16th, 2021

DOI: https://doi.org/10.21203/rs.3.rs-228614/v1

License: (c) (i) This work is licensed under a Creative Commons Attribution 4.0 International License. Read Full License 


\section{Abstract}

\section{Background}

Patients with ovarian cancer (OC) often suffer from depressive symptoms, but there is little research on coping style such as perceived social support and resilience. The aim of the present study was to explore whether resilience plays a mediating role between perceived social support and depressive symptoms.

\section{Methods}

A cross-sectional study was performed between August 2018 and March 2019. Perceived social support, resilience, and depressive symptoms were measured with the Multi-dimensional Scale of Perceived Social Support (MSPSS), the Center for Epidemiologic Studies-Depression (CES-D) scale and the ConnorDavidson Resilience Scale (CD-RISC). Hierarchical linear regression analyses were used to assess the mediating role of resilience between these variables.

\section{Results}

Of 230 consecutive patients identified, a total of 217 completed questionnaires. After controlling for covariates, perceived social support was negatively correlated with depressive symptoms $(\beta=-0.482, p<$ 0.01 ) and explained $22.8 \%$ of the variance. In addition, after controlling for covariates and perceived social support, resilience was also negatively associated with depressive symptoms $(\beta=-0.492, p<0.01)$ and explained $18.1 \%$ of the variance. Bootstrapping test confirmed that the $\mathrm{BCa} 95 \% \mathrm{Cl}$ for resilience excludes 0 in Table 4 (BCa95\% Cl: $-0.342,-0.143)$, therefore resilience partially mediated the associations of perceived social support with depressive symptoms.

\section{Conclusions}

Results revealed that resilience could mediate the association between social support and depressive symptoms, and concluded that it was critical to focus on social support as well as resilience in the management strategy of OC.

\section{Full Text}

Due to technical limitations, full-text HTML conversion of this manuscript could not be completed. However, the manuscript can be downloaded and accessed as a PDF. 